\title{
Big placenta and anaemia in pregnancy
}

\author{
Mahamuda Begum ${ }^{1}$, Shamim Ara ${ }^{2}$, Shahnaz Begum ${ }^{3}$, Segupta Kishwara ${ }^{4}$, Khondaker Abu Rayhan ${ }^{5}$, \\ Asad Hossain ${ }^{6}$, Anjuman Nahar ${ }^{7}$
}

\begin{abstract}
:
Background: Birthing process is the journey of the spirit/ soul. The Placenta is the home for this spirit/ soul for nine months. Placenta has a huge role to play throughout the pregnancy acting as the kidneys, lungs and intestines all in one ${ }^{1}$. Placenta is an organ that is essential to the survival and growth of the fetus of the mammals. Anaemia in pregnancy is common and one of the risk factors in pregnancy. Maternal anaemia result in fetal hypoxemia and also stimulates placental growth. In anaemia, significant changes both in gross morphology and in histology of the placenta can occur.
\end{abstract}

Type of study: Descriptive.

Place of study: Department of Anatomy, Dhaka Medical College, Dhaka.

Study period: July 2005 to June 2006.

Methods: Sixty (60) placentas of Bangladeshi pregnant women were studied. Out of 60 placentas, anaemic and control group were 40 and 20 respectively. The study was designed to determine, morphological changes of placenta which is influenced by maternal anaemia. Macroscopic dimension of the placenta were measured with observation and dissection method. The samples were divided into group A (control), group B1 (mild anaemia), group B2 (moderate anaemia) and group B3 (severe anaemia). The severe group was not found in present study.

Result: In anaemia, placental diameters, surface area and thickness were increased.

Conclusion: There were morphological changes of the placenta in association with maternal anaemia. However, comprehensive work considering the physiological, biochemical, genetic as well as further gross, light, electron microscopic and morphometric placental studies are needed in order to support the findings of present study.

\section{Keywords: Placenta, anaemia, pregnancy.}

Introduction: The placenta is vital for the maintenance of a normal pregnancy. Fetal growth and well-being depend on the structural and functional component of the placenta. Placental hypertrophy associated with maternal anaemia, which is probably a compensatory physiological response to ensure adequate oxygen supply to the fetus ${ }^{2}$. Maternal anaemia causes the development of a big placenta ${ }^{3}$. Babies born with a disproportionately large placenta are at greater risk for hypertension in later life ${ }^{4}$.

\footnotetext{
1. Associate Professor (cc), Department of Anatomy, Dhaka Community Medical College, Dhaka

2. Professors Head, Dept. of Anatomy, Dhaka Medical College, Dhaka

3. Associate Professor, Dept. of Anatomy, Shaheed Suhrawardy Medical College, Dhaka

4. Asstt. Professor (cc), Dept. of Anatomy, Dhaka Medical College, Dhaka

5. Asstt. Professor, Dept. of Anatomy, Southern Medical College, Chittagong.

6. Asstt. Professor, Dept. of Anatomy, Dhaka Medical College, Dhaka

7. Asstt. Professor, Dept. of Anatomy, Ibne Sina Medical College, Dhaka Correspondence: Dr. Mahamuda Begum
}

It undergoes continuous change in weight, structure, shape, and function throughout gestation in order to support prenatal life ${ }^{5}$. The WHO report shows anaemia prevalence at the global level as 55.9 percent among the expectant mothers. In pregnancy, anaemia has a significant effect on placenta. Maternal mortality due to anaemia in Bangladesh was 4 percent in $1991^{6}$. According to WHO, a level of Haemoglobin below $11 \mathrm{gm} / \mathrm{dl}$ during pregnancy is an indication of anaemia. But in South Asia, anaemia is diagnosed when the lowest antenatal haemoglobin is $<10 \mathrm{~g} / \mathrm{dl}^{4}$.

\section{Materials and Methods:}

This study was carried out on 60 placentas from Bangladeshi mothers. The mothers were selected as who were suffering from antenatal anaemia i.e. having haemoglobin level below $10 \mathrm{gm} / \mathrm{dl}$ at any time before delivery 4 and those having haemoglobin level at or above $10 \mathrm{gm} / \mathrm{dl}$ were selected as control group, and gestational age of both groups was from 36 to 40 weeks. 
Placentas were collected from Gynaecology \& Obstetric Department of Dhaka Medical College Hospital and Azimpur Maternity, Dhaka within 6 (six) hours of delivery. After collection of placentas, grouping was done according to mother's heamoglobin concentration.

\section{Parameters studied:}

1. Diameter of the placenta

2. Surface area of the placenta

3. Thickness of the placenta

4. Maternal anaemia

\section{Haemoglobin estimation of mother}

Verbal consent was collected before collection of venous blood for haemoglobin estimation.

\section{Procedure of Haemoglobin Estimation}

Photoelectric Colorimeter analyzed haemoglobin content using the standard procedure of cyanmethoglobin method. With a disposable sterile 3 cc syringe drew mother's venous blood less then 1 cc. Blood sample was carried in Biochemistry Department of Dhaka Medical College, Dhaka in a glass vial with anticoagulant ${ }^{7}$.

\section{Placenta! measurement procedure:}

Each collected placenta was placed on a metallic tray and umbilical cord was cut at the insertion site. The placenta was cleaned with tap water until appearance of clear washout water and then the placenta was fixed in $10 \%$ formol saline solution.

\section{Measurement of the surface area of the Placenta}

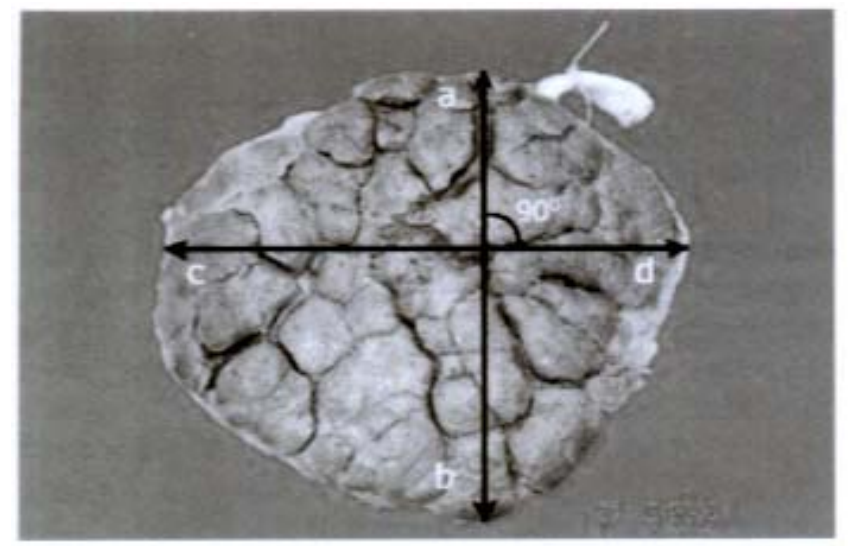

Photo 2: Photograph of the maternal surface of the placenta showing the procedure of the measurement of its diameter, $t$ he line ab shows the apparently maximum diameter, while line cd shows the apparently maximum diameter at right angle to line ab (after Shanklin 1958 cited in Chowdhury 2002).

The tracing of the placental margin were made on the white plain paper and the surface area of the Placenta was calculated from this tracing by using a Planometer (Photo 2 following S. Khanna, 1978). A $10 \mathrm{~cm} \mathrm{x} 10 \mathrm{~cm}$ block was drawn on a graph sheet. Then fixed the planometer on the graph sheet and set planometer's scale to zero (0) unit. After fixing of the planometer, the block was measured 5 times for getting a mean value for the (10 $\mathrm{cm} \times 10 \mathrm{~cm}$ ) or $100 \mathrm{~cm}^{2}$ block. This mean value was used to get a factor value for $100 \mathrm{~cm}^{2}$ block. The measured values were $0.68,0.70,0.66,0.71 \& 0.70$ and the mean value was 0.69 .

Planometer value 0.69 is found for $100 \mathrm{~cm}^{2}$ area Planometer value 0.69 is $100 / 0.69$ area $=144.93 \mathrm{~cm}^{2}$

Each placenta was measured 5 (five) times using the planometer and got a mean value for each placenta. The mean of the measured value of the placenta was simply multiplied by the factor 144.93 to get the surface area of each placenta in $\mathrm{cm}^{2}$.

\section{Measurement of diameter of the Placenta}

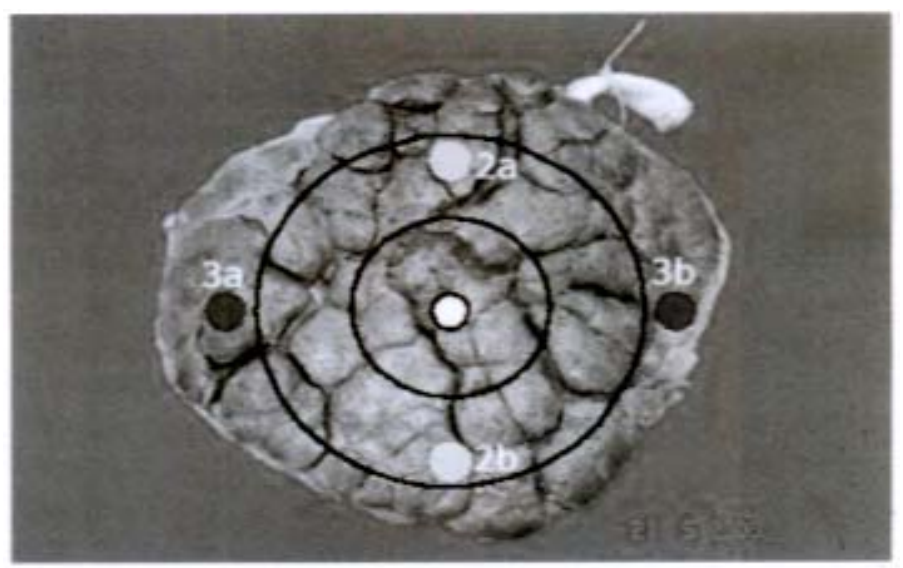

Photo 3: Photograph of the maternal surface of the placenta with division into three zones, showing the points for the measurement of its thickness.

- White circle indicate the central zone

- Yellow circle indicate the middle zone

- Blue circle indicate the outer zone.

The trimmed Placenta was placed in a dry metal tray keeping the maternal surface upward. The maximum diameter was measured with a metallic scale "in centimeter $(\mathrm{cm})$. A second maximum diameter was measured at right angles to the first one. The mean of the two measurements was considered as diameter of the Placenta (Photo 3 following Shanklin 1958 cited in Chowdhury 2002).

\section{Measurement of thickness of the Placenta}

The thickness of the Placenta was measured in $\mathrm{cm}$ by a large needle in five points of each Placenta. All the placentas were placed on foetal surface.

To have uniform five points in each Placenta was divided 
into three zones by two arbitrary circles, which cut the radius of the Placenta into three equal lengths from center to periphery. One thickness was measured from the center of the central zone, two from middle and two from peripheral zone. The peripheral points lie on two arbitrary circles, which meet at the center at right angle (Photo 3). The mean of the five measurements was calculated and considered as thickness of the Placenta (following Anwar 1999, cited in Chowdhury 2002)

\section{Data processing}

The data collected from the morphological studies were processed to get mean values, standard deviations, percentage values etc, as applicable and appropriate statistical analysis were done by Anova test and multiple compares was done by Post hoc in LSD (Least significant difference), to detect significance of differences between corresponding findings in groups using SPSS.

\section{Observation and Result}

The present study was carried out on 60 human placentas. All placentas were collected after 36 weeks of pregnancy. Out of 60 placentas, 20 were from control mothers (A), who were not anaemic (10.5 $\mathrm{gm} / \mathrm{dl}$ ), 27 from mothers having mild anaemia (B1) $(9.2 \mathrm{gm} / \mathrm{dl})$ and 13 from mothers who were moderately anaemic (B2) $(7.2 \mathrm{gm} / \mathrm{dl})$. No severe anaemic (B3) mother was found during the period of collection of placenta for this study.

(Table-1) shows the haemoglobin level of mothers in different groups, mean haemoglobin level in control group was $10.5 \mathrm{gm} / \mathrm{dl}$. Mean haemoglobin level in mild and moderate groups was as $9.2 \mathrm{gm} / \mathrm{dl}$ and 7.2 $\mathrm{gm} / \mathrm{dl}$ respectively. Analysis was done according to the groups based on severity of anaemia and control group.

Table 1: Haemoglobin level in different groups Group Number of subjects (n) Average Haemoglobin Level (gm/dl)

\begin{tabular}{|l|l|l|}
\hline Group & $\begin{array}{l}\text { Number of subjects } \\
(\mathrm{n})\end{array}$ & $\begin{array}{l}\text { Average Haemoglobin } \\
\text { Level (om/dl) }\end{array}$ \\
\hline A & 20 & $10.50(12-10)$ \\
\hline 81 & 27 & $9.20(8-9.2)$ \\
\hline B2 & 13 & $7.20(6.5-7.2)$ \\
\hline
\end{tabular}

Group A = Control

Group B1 = Case (Mildly Anaemic)

Group B2 = Case (Moderately Anaemic)

\section{Diameter of the placenta}

It was evident from Table $2 \&$ Fig. 2 that the mean $( \pm S D)$ diameters of the placenta were $15.60+0.74,18.0411 .32$ and $18.80 \pm 1.96$ in group A, B1 \& B2 respectively. Diameter of the placenta was greater in anaemic groups than the control groups and was statistically significant $(p<0.001)$ between group A \& B1 and between group A \& B2

\section{Thickness of the placenta}

From the findings of the present study and Table $2 \&$ Fig. 3 , it was observed that the mean difference in thickness of placenta between groups A, B1 and B2 were not significant $(\mathrm{p}>0.1)$.

Table 2:

\begin{tabular}{|c|c|c|c|c|}
\hline Group & $n$ & $\begin{array}{l}\text { Surface area } \\
\text { (in sq.cm) } \\
\text { Mean+SD }\end{array}$ & $\begin{array}{l}\text { Diameter } \\
(\text { in cm) } \\
\text { MeantSD }\end{array}$ & $\begin{array}{l}\text { Thickness } \\
(\text { in cm) } \\
\text { Mean } \pm \text { SD }\end{array}$ \\
\hline 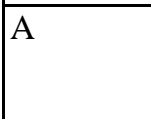 & 20 & $\begin{array}{l}219.26 \pm 4.59 \\
(210.15226 .65)\end{array}$ & \begin{tabular}{|l|}
$15.60 \pm 0.7$ \\
$\Delta$ \\
$(14.017 .0)$
\end{tabular} & $\begin{array}{l}2.14 \pm 0.26 \\
(1.93 .0)\end{array}$ \\
\hline B1 & 27 & $\begin{array}{l}231.74 \pm 6.02 \\
(221.52246 .54)\end{array}$ & $\begin{array}{l}18.04 \pm 1.3 \\
(16.021 .0)\end{array}$ & $\begin{array}{l}2.10 \pm 0.16 \\
(1.92 .5)\end{array}$ \\
\hline B2 & 13 & $\begin{array}{l}235.12 \mathrm{H} 1.23 \\
(223.41260 .20)\end{array}$ & $\begin{array}{l}18.80 \pm 1.9 \\
c \\
(16.523 .0)\end{array}$ & $\begin{array}{l}2.19 \pm 0.13 \\
(2.02 .4)\end{array}$ \\
\hline $\begin{array}{l}\text { Rvalue } \\
\text { AvsB1 } \\
\text { AvsB2 }\end{array}$ & & $\begin{array}{l}<0.001 * * * \\
0.00 r^{* *}\end{array}$ & $\begin{array}{l}\text { o.oor** } \\
<0.001 * "\end{array}$ & $\begin{array}{l}>0.50 \mathrm{~ns} \\
>0.10 \mathrm{~ns}\end{array}$ \\
\hline B1 vs B2 & & $>0.10 \mathrm{~ns}$ & $>0.05 \mathrm{~ns}$ & $>0.10 \mathrm{~ns}$ \\
\hline
\end{tabular}

Group A $\bullet$. Control

Group B1 : Case (mildly anaemic)

Group B2 : Case (moderately anaemic)

Figures in parentheses indicate range. Statistical analysis done by ANOVA (multiple comparison), ns $=$ not significant, $* * *=$ significant

\section{Surface area of placenta}

Table 2 \& Fig. 1 showed the mean $( \pm \mathrm{SD})$ surface area of placenta were A, B1 and B2. The mean difference in surface area between groups A and group B1, group A and groupB2 were statistically significant $(\mathrm{p}<0.001)$.

Discussion: This study was carried out on the human placenta of anaemic mothers of different ages. Morphological and histological analyses of the placentas were performed and the findings were compared between mild versus moderate anaemia, control group versus mild and moderate anaemic group. Aim of this study was to search for any correlation between the features of placenta in control and anaemic group depending on the status of 
the mother in terms of haemoglobin level, gestational age. Thagaleeta et al. ${ }^{8}$ observed a significant difference in diameter among different groups. Their highest mean diameter was $14.55 \mathrm{~cm}$ in control group which is contradictory to the observation of the present study. The highest diameter was $18.80 \mathrm{~cm}$ in moderate anaemia in current study. It is at highly significant level $(\mathrm{p}<0.001)$.

Khanna et $\mathrm{al}^{9} .1998$ observed that the surface area of placenta remain unchanged in their study groups. In present study the observation of the placental surface area were highest $\left(235.12 \mathrm{~cm}^{2}\right)$ in moderate anaemia as compared to control group $\left(219.26 \mathrm{~cm}^{2}\right)$ that is highly significant $(\mathrm{p}<0.001)$.

Placental weight and thickness has been taken as an indicator of placental function. Increases in placental weight in case of maternal anaemia have therefore, frequently been interpreted as evidence of compensatory hypertrophy for reduced oxygen supply. Lao and Wong 1997 studied with the morphology of the placenta. They found out that the placental weight and thickness was higher in anaemic group as compared to the controls. Braumann ${ }^{10}, 1993$ observed that in hypoxic condition like anaemia, thickened placenta causes reduced birth weight due to blood flow and oxygen supply is happened in edematous thickened placenta.

\section{Reference}

1. Godfrey, K.M., Redman, C.W.G., Barker, D.J.P. \&
Osmond, C. The effect of maternal anaemia and iron deficiency on the ratio of Arulkumaran S, editors. Obstetrics and Gynaecology for Post Graduation. 2nd ed. Chennai: Orient Longman Limited ; 1999. 2 - 3.

2 Anpei Hung, Rendong Zhang, Zhengwei Yang. Quantitative study of placental structure in women with pregnancy iron deficiency fetal weight to placental weight. $\mathrm{Br} \mathrm{J}$ Obstet and Gynaecol 1991; 98: 886-91.anaemia: Eur.J Obstet Gynecol \& Epi. Biol 97(2001)59-64.

3. Rao KB. Safe Mother hood. In : Ratnam SS, Rao KB, 4. Lao T. T, Wong WM. Placental ratio - its relationship with mild maternal anaemia : Placenta 1997; 18 : 593 - 596.

5. Gambling L, Harry JM.The effect of nutrient deficiency on fetal development, Pregnancy outcome and adult metabolism: Rowett Research Institute 2003; 46: 130-141

6 Bhuiyan SN, Perveen R, Begum R, Hussain A LM. Cllinical guide to Obstetrics and Gynaecology. 2nd ed, Dhaka, Bangladesh :1997; p. 729 - 34.

7. Amin R, Reza S. Laboratory Manual for practical physiology and biochemistry: 1st ed. Dhaka: Medicogist; 2005. 396 - 406.

8 Thangaleeta T, Vijayalaksmi P. Impact of anaemia in pregnancy : Ind J Nutri and Diet 1994; 31 (9): 251 - 256.

9 Singla P.N, Chand S, Khanna S, Agarwal K. N. Effect of maternal anaemia on the placenta and the new born infant : Acta Paediatr Scand 1978; 67 : 645-648.

10. Braumann c, Anaemia in obstetrics : chreymann@bluewin.ch 